SANTOS, G.R.; CAFÉ-FILHO, A.C.; LEÃO, F.F.; CÉSAR, M.; FERNANDES, L.E. Progresso do crestamento gomoso e perdas na cultura da melancia. Horticultura Brasileira, Brasília, v.23, n.2, p.228-232, abr-jun 2005.

\title{
Progresso do crestamento gomoso e perdas na cultura da melancia ${ }^{1}$
}

Gil R. dos Santos ${ }^{1,2}$; Adalberto C. Café-Filho ${ }^{2}$; Fernando F. Leão ${ }^{1}$; Marcos César ${ }^{1}$, Luzia E. Fernandes ${ }^{1}$

${ }^{1}$ Universidade Federal de Tocantins, C. Postal 66, 77400-000 Gurupi-TO; ²Universidade de Brasília, depto. Fitopatologia, 70910-900 Brasília-DF.

\section{RESUMO}

O progresso do crestamento gomoso e as perdas na cultura da melancia foram estudados em ensaios de campo com inoculação artificial de Didymella bryoniae. Para o estudo do progresso da doença foram utilizadas duas áreas indenes, cada uma com 24 x 32 m, e nenhuma medida de controle foi adotada. Para obtenção das curvas de progresso, quantificou-se a percentagem média de área foliar afetada em uma área de $768 \mathrm{~m}^{2}$, aos 45, 50, 55, 60, 65, 74, 80 e 87 dias após o plantio (DAP). Ficou demonstrado que a doença progride segundo o modelo exponencial, mesmo sob condições não muito favoráveis, na ausência de chuvas e com baixo nível de inóculo inicial. Os valores máximos de severidade foram observados aos 87 DAP (12,5-13,6\% da área foliar doente). No ensaio de perdas, utilizou-se o delineamento experimental de blocos casualizados com cinco tratamentos e quatro repetições. Cinco níveis de doença foram obtidos pela aplicação de doses decrescentes da mistura clorotalonil e tiofanato metílico (g/100 L de água): (a) 0,0 g i.a. (testemunha); (b) clorotalonil $25 \mathrm{~g}+$ tiofanato metílico $10 \mathrm{~g}$; (c) clorotalonil $75 \mathrm{~g}+$ tiofanato metílico; $30 \mathrm{~g}$; (d) clorotalonil $125 \mathrm{~g}+$ tiofanato metílico $50 \mathrm{~g}$; (e) clorotalonil $250 \mathrm{~g}+$ tiofanato metílico 100 g. A doença foi avaliada uma única vez, aos 78 DAP por meio de uma escala de notas de 0 a 9, baseada na porcentagem de área foliar doente. A severidade máxima foi observada aos 78 DAP na testemunha (26,5\% de área foliar doente). Houve alta $(r=-0,96)$ correlação negativa entre os níveis da doença nas folhas e a produção de frutos, com redução de até $19,2 \%$ na produtividade da melancia devido ao crestamento gomoso do caule. O controle químico foi eficiente a partir da dosagem de clorotalonil $125 \mathrm{~g}+$ tiofanato metílico $50 \mathrm{~g}$.

\section{ABSTRACT \\ Disease progress and crop losses due to watermelon gummy stem blight}

Progress and losses due to gummy stem blight were studied in field plots artificially inoculated with Didymella bryoniae. For the temporal disease progress study, two fields ( 24 x $32 \mathrm{~m}$ ) were established in areas free of the disease, without any history of cucurbit cultivation, and no control measures were applied. Data for the disease progress curves were obtained from the mean diseased leaf area in an area of $768 \mathrm{~m}^{2}$, at $45 ; 50 ; 55 ; 60 ; 65 ; 74 ; 80$ and 87 days after planting (DAP). Disease progressed according to the exponential model, even under marginally favorable environmental conditions. Maximum severity values were observed 87 DAP (12.5-13.6\% diseased leaf area). The crop loss experiment was laid out in a randomized completed block design with five disease levels and four replicates. Disease levels were obtained with the application of five fungicide doses (per $100 \mathrm{~L}$ of water) of a mixture of active ingredients chlorothalonil and methyl thiophanate, as follows: (a) $0 \mathrm{~g}$ a.i. (control); (b) chlorothalonil $25 \mathrm{~g}+$ methyl thiophanate $10 \mathrm{~g}$; (c) chlorothalonil $75 \mathrm{~g}+$ methyl thiophanate $30 \mathrm{~g}$; (d) chlorothalonil $125 \mathrm{~g}+$ methyl thiophanate $50 \mathrm{~g}$; (e) chlorothalonil $250 \mathrm{~g}+$ methyl thiophanate $100 \mathrm{~g}$. Disease severity was evaluated once, 78 DAP, with a disease scale ranging from 0 to 9 , based on the percentage of diseased leaf area. Maximum disease levels were observed 78 DAP in control plots ( $26.5 \%$ diseased leaf area). There was high negative correlation $(\mathrm{r}=-0.96)$ between disease levels and fruit yield. Yield losses due to gummy stem blight reached $19.2 \%$ and chemical control reduced disease levels significantly.

Keywords: Citrullus lanatus, epidemiology, control.

Palavras-chave: Citrullus lanatus, epidemiologia, controle.

\section{(Recebido para publicação em 17 de dezembro de 2003 e aceito em 10 de janeiro de 2005)}

\begin{abstract}
$\mathrm{A}$ melancia (Citrullus lanatus) é importante cultura para o Brasil, pela demanda intensiva de mão-de-obra rural e o excelente retorno econômico para o produtor. Segundo a FAO (2002), no Brasil, a melancia ocupa uma área de 82.000 ha e um volume de produção de $620.000 \mathrm{t}$, com produtividade média de 7,56 t/ha. Entre os maiores produtores estão SP, RS, BA, GO e TO (ALENCAR, 2001). No estado do Tocantins, a cultura é plantada em cerca de 3.000 ha (CÉSAR; SANTOS, 2001), com produtividade média de 30 t/ha (SANTOS et al. 2001).

Dentre os fatores limitantes à produção, as doenças têm provocado grandes
\end{abstract}

perdas na produtividade e na qualidade dos frutos. Por afetarem a aparência do produto, pequenas manchas na casca da melancia podem levar ao descarte do fruto, além de encarecer o custo de produção com o uso excessivo de defensivos (CÉSAR; SANTOS, 2001). Dentre as doenças da melancia, o crestamento gomoso do caule é uma das principais (SANTOS et al. 2003). Os sintomas incluem cancro no caule, queima das folhas e apodrecimento de frutos (SCHENCK, 1968). A doença vem despertando preocupação também nos perímetros irrigados do nordeste (DIAS et al. 1996), e em outros países como nos Estados Unidos
(EVERTS, 1999; KEINATH; DUTHIE, 1998; SITTERLY; KEINATH, 1996; SCHENCK, 1960) e no Caribe tropical (BALA; HOSEIN, 1986). O agente causal é o fungo Didymella bryoniae (Auersw) Rehm (=Mycosphaerella citrullina (C.O. Sm.) Gross.), anamorfo Ascochyta cucumis Fautrey \& Roum. (=Phoma cucurbitacearum (Fr.: Fr.) Sacc.), e tem como hospedeiro diversas espécies de Citrullus, Cucumis, Cucurbita, e outros gêneros (KEINATH, 1995). Existem poucas cultivares de melancia e de outras cucurbitáceas, com boa aceitação comercial, e resistência a $D$. bryoniae (DIAS et al. 1996; MCGRATH et al

${ }^{1}$ Parte da tese de doutorado em Fitopatologia do primeiro autor a ser apresentada à Universidade de Brasília, Brasília-DF 
1993; SUMNER e Hall, 1993; WEHNER; AMAND, 1993).

O controle da doença com fungicidas tem sido utilizado (KEINATH, 1995), porém sua baixa eficiência tem sido atribuída à rápida infecção das folhas pelo patógeno (ARNY; ROWE, 1991; VAN STEEKELENBURG, 1985), ou às populações de $D$. bryoniae resistentes aos benzimidazóis, quando este ingrediente ativo é utilizado (MALATHRAKIS; VAKALOUNAKIS, 1983). Trabalhos relacionando níveis de severidade nas folhas com a produtividade da cultura não foram encontrados na literatura nacional. Porém, em estudos realizados em outros países, as perdas por D. bryoniae variam de $17 \%$ (KEINATH et al. 1997) a 43\% (KEINATH; DUTHIE, 1998). No Brasil, Figueiredo et al. (1966), observaram que a severidade do crestamento gomoso em frutos de aboboreira de moita variou de 19 a $51 \%$ dependendo da época de semeadura, porém não houve quantificação de perdas. Trabalhos envolvendo o progresso da doença em condições de campo também são escassos no mundo e inexistentes nas condições nacionais. Estudos epidemiológicos são importantes para determinar estratégias eficientes de controle. Por essa razão, este trabalho teve por objetivo estudar o progresso do crestamento gomoso e as perdas na cultura da melancia.

\section{MATERIAL E MÉTODOS}

\section{Progresso do crestamento gomoso}

O progresso do crestamento gomoso foi estudado em duas áreas de 24 x 32 m cada uma, distanciadas $10 \mathrm{~m}$ uma da outra, onde anteriormente foi cultivado arroz, e sem histórico de plantio de cucurbitáceas nos últimos 10 anos. O estudo foi realizado no período de 26 de junho a 21 de setembro de 2003. Cada área foi subdividida em quadrantes com dimensões de 2 × $2 \mathrm{~m}$. O preparo do solo constou de aração e gradagem. A adubação de base foi feita com $650 \mathrm{~kg} / \mathrm{ha}$ da fórmula 05-25-15 de N-P-K. A cultivar utilizada foi a Crimson Sweet, suscetível à doença, e atualmente a mais plantada em todo o território nacional por ser produtiva e ter boa aceitação no mercado nacional. A adubação de cober- tura foi feita de $200 \mathrm{~kg} / \mathrm{ha}$ da fórmula 30-00-20 de N-P-K. A irrigação na área foi feita diariamente a partir das 17:00 h por aspersão, por um período de 40 minutos e as capinas foram feitas manualmente. Não foram utilizados fungicidas ou inseticidas durante a condução do trabalho. Aos 34 dias após o plantio (DAP) foi feita inoculação de uma planta localizada no centro de cada área utilizando-se um pedaço de caule de $10 \mathrm{~cm}$ naturalmente infectado obtido em cultivo comercial infestado pelo crestamento gomoso do caule. Após ferimento do colo por fricção com o fragmento infectado, este foi depositado ao lado da planta inoculada. A planta inoculada foi envolvida por saco plástico e algodão embebido de água esterilizada, como câmara úmida, por 48 h. Essa planta serviu como foco inicial da doença.

As duas áreas foram mapeadas, situando-se todas as plantas. Quando os primeiros sintomas da doença foram observados nas folhas, iniciou-se o monitoramento dentro de cada quadrante, utilizando-se a escala de notas de 0 a 9, onde: 0-planta sadia; 1menos de $1 \%$ da área foliar afetada; 3 entre 1 a $5 \%$ da área foliar afetada; 5entre 6 a $25 \%$ da área foliar doente; 7 entre $26-50 \%$ da folha doente; 9-mais que $50 \%$ da área foliar afetada. Para obtenção das curvas de progresso da doença, converteram-se as notas para porcentagens de área foliar doente pelo ponto médio de cada nota, em cada uma das duas áreas estudadas (média de 192 quadrantes, com áreas totais de $768 \mathrm{~m}^{2}$ ) aos 45; 50; 55; 60; 65; 74; 80 e 87 DAP. A proposição do modelo de progresso foi feita através da inspeção da forma das curvas de progresso. As variáveis climáticas (temperatura máxima, mínima e umidade relativa do ar), foram monitoradas na altura do dossel das plantas $(20 \mathrm{~cm})$ utilizando-se um termohigrômetro digital.

Perdas de produtividade devidas ao crestamento gomoso do caule

$\mathrm{O}$ experimento foi instalado na área experimental da Universidade Federal do Tocantins, Campus de Gurupi. Utilizou-se o delineamento experimental de blocos casualizados com cinco tratamentos e quatro repetições. Foram utilizadas parcelas de
$10 \times 6 \mathrm{~m}$, com um total de 12 plantas semeadas no espaçamento de 2,0 x 2,0 m, e cv. Crimson Swet. O preparo do solo, espaçamento, adubação, semeadura, cultivar, capinas e método de irrigação foram os mesmos do ensaio anterior. Os tratamentos foram diferentes intensidades da doença obtidas pelas doses (por $100 \mathrm{~L}$ de água) da mistura clorotalonil e tiofanato metílico, ingredientes ativos (i.a) do produto comercial, (p.c.) Cerconil: a - 0,0 g i.a. (testemunha); b - clorotalonil $25 \mathrm{~g}+$ tiofanato metílico $10 \mathrm{~g}$; c - clorotalonil $75 \mathrm{~g}+$ tiofanato metílico $30 \mathrm{~g}$; d - clorotalonil 125 $\mathrm{g}+$ tiofanato metílico $50 \mathrm{~g}$; e - clorotalonil $250 \mathrm{~g}+$ tiofanato metílico $100 \mathrm{~g}$.

Cada parcela foi inoculada aos 30 dias após o plantio (DAP), utilizandose pedaços de $10 \mathrm{~cm}$ de caule com lesões obtidos de área comercial naturalmente infestada pelo crestamento gomoso do caule. A inoculação foi feita por ferimento do colo e deposição do inóculo ao lado da planta inoculada como descrito acima. As pulverizações foram iniciadas aos 40 DAP, quando se observaram os sintomas iniciais da doença. Para aumentar a persistência do fungicida, utilizou-se espalhante adesivo (resina sintética emulsionada $387 \mathrm{~g} /$ $\mathrm{L}+$ agente tensoativo aniônico $129 \mathrm{~g} / \mathrm{L}$ + água $516 \mathrm{ml} / \mathrm{L}$ ) que foi misturado ao fungicida na dose de $50 \mathrm{ml} / 100 \mathrm{~L}$ de água. Os tratamentos foram aplicados semanalmente, após a irrigação, utilizando-se um pulverizador costal a um volume de aplicação de $300 \mathrm{~L} / \mathrm{ha}$, até 10 dias antes da colheita, totalizando 5 pulverizações. Foram quantificadas a percentagem de área foliar doente e a produtividade. A doença foi avaliada aos 78 DAP por meio da escala de notas de 0 a 9 , descrita anteriormente. Antes das análises de regressão, as notas foram convertidas para porcentagens de área foliar doente pelo ponto médio de cada nota e os dados transformados pelo arco seno da raiz quadrada para atender as pressuposições da análise estatística. A colheita e a pesagem dos frutos foram realizadas aos 78 DAP, considerandose apenas os frutos com padrão de peso comercial $(\geq 5,0 \mathrm{~kg})$.

Foram ajustados modelos de regressão para área foliar doente vs. doses de fungicida e produtividade vs. doses de fungicida, e de correlação para as curvas de produtividade vs. área foliar doente. 


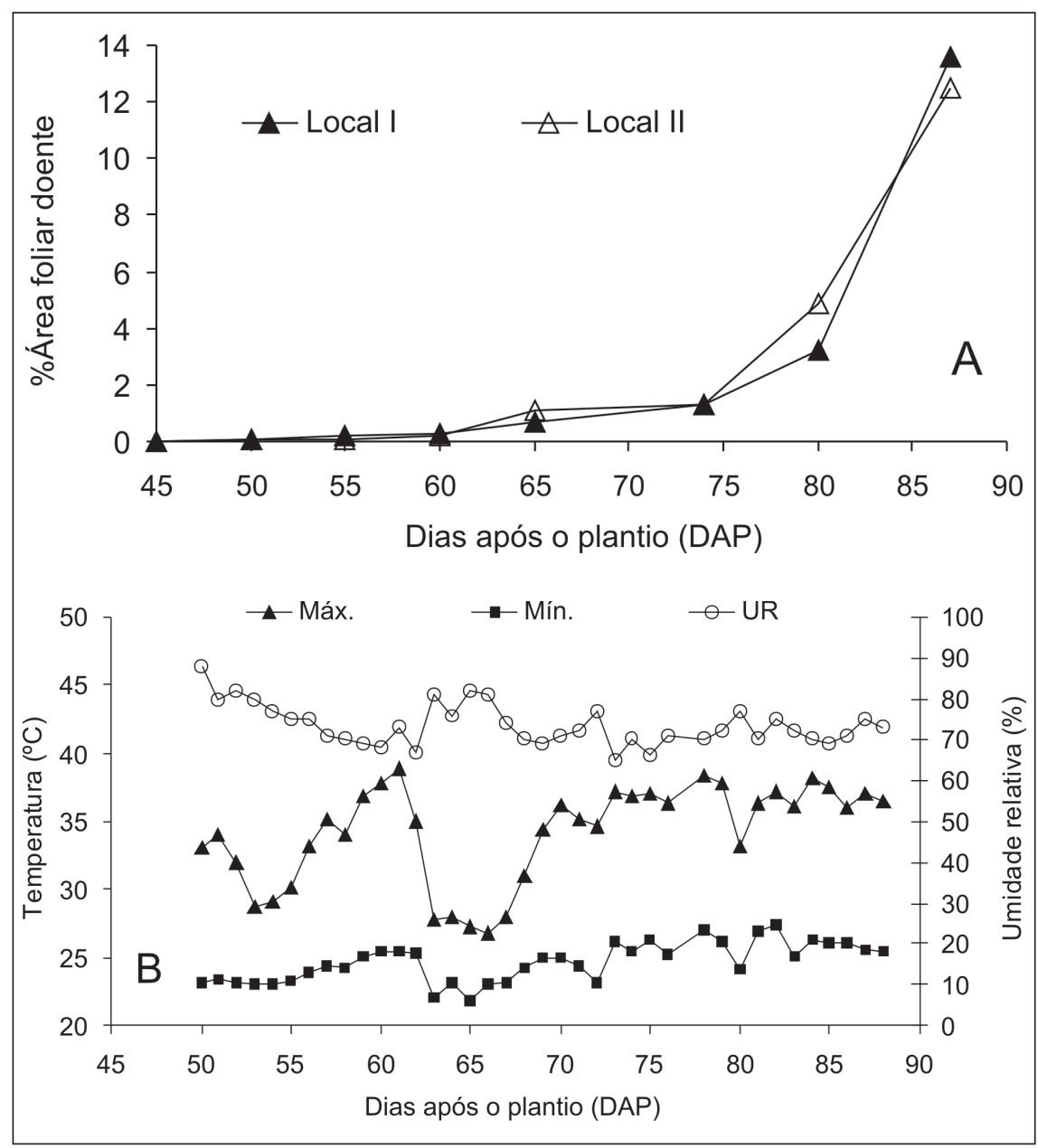

Figura 1. Progresso do crestamento gomoso em folhas de melancia (A), a partir de um foco inicial na cv. Crimson Sweet, em dois locais; Temperaturas máxima e mínima $\left({ }^{\circ} \mathrm{C}\right)$ e umidade relativa do ar (B) a partir de 50 dias após o plantio. Gurupi, UFT, 2003.

\section{RESULTADOS E DISCUSSÃO}

Progresso do crestamento gomoso

Aos quatro dias após a inoculação, observou-se encharcamento do tecido do caule. Com o desenvolvimento da doença, ocorreu exsudação de cor marrom no local afetado, onde posteriormente, ocorreu necrose na base do caule e observaram-se numerosos picnídios escuros. Os sintomas nas folhas foram verificados a partir de 50 DAP, nos dois locais estudados (Figura 1A). Surgiram manchas pardo-escuras, circulares e em estágios mais avançados formaram-se picnídios correspondendo ao anamorfo Ascochyta cucumis, com patogenicidade comprovada posteriormente por meio da inoculação de plantas testes em melancia em casa de vegetação.

Até 74 DAP, a doença nas folhas aumentou de maneira aproximadamen- te linear nos dois locais avaliados. A partir de 75 DAP, as curvas de progresso apresentaram forma exponencial (Figura 1A). $\mathrm{O}$ aumento progressivo da doença a partir dos 75 DAP relacionouse com o início da colheita dos frutos, quando normalmente ocorrem injúrias nos ramos e nas folhas que são portas de entrada para o patógeno. Além disso, quando o tecido é mecanicamente afetado, ocorre exsudação de nutrientes importantes para o processo de infecção (SVEDELIUS; UNESTAN, 1978). Chiu e Walker (1949), verificaram que a germinação dos esporos de A. cucumis foi estimulada pelos extratos das plantas.

Os valores máximos de área foliar doente obtidos nas duas áreas foram de $12,5 \%$ e de $13,6 \%$. A intensidade da doença pode ser considerada alta, dado que o local era indene e a epidemia de crestamento em cada área foi iniciada por apenas um foco. As condições climáticas não foram ótimas para o desenvolvimento da doença, já que o ensaio foi instalado no verão, sem ocorrência de chuvas e umidade relativa inferior à ideal para a doença (Figura 1B). A severidade final foi cerca da metade da verificada na testemunha do ensaio de perdas $(26,5 \%)$. Isso pode ser atribuído à inoculação mais precoce no ensaio de perdas (30 DAP) e a sua instalação em área onde já se havia observado a doença em plantios anteriores. Por ser uma doença de disseminação por respingos, o número de focos por área tem grande efeito na taxa de progresso da epidemia. Observou-se que o patógeno após infecção inicial no caule, dissemina-se para as folhas da planta.

Em um trabalho pioneiro, Cardoso et al. (1974), relacionaram umidade relativa do ar, temperatura, pluviosidade, ocorrência de ascósporos de $M$. melonis (=Didymella bryoniae) e podridão de frutos de abóbora de moita (Cucurbita реро). Os autores verificaram que a liberação dos ascósporos ocorre após cerca de uma hora depois de cessado o período de precipitação, associado à temperatura média entre 18 a $25^{\circ} \mathrm{C}$ e umidade relativa do ar superior a $85 \%$. A doença se desenvolveu rapidamente em condições de umidade relativa elevada. Durante a condução do ensaio de progresso a temperatura máxima foi acima de $30^{\circ} \mathrm{C}$ e a mínima foi superior a $22^{\circ} \mathrm{C}$. A umidade relativa foi de $70 \%$ nos horários mais frios do dia e à noite, abaixo, portanto, das condições ideais descritas por Cardoso et al. (1974) (Figura 1B). Ainda assim, estas condições, aliadas à irrigação por aspersão, permitiram a disseminação do patógeno e foram suficientes para a infecção foliar, provavelmente à noite, associada a períodos mais prolongados de molhamento foliar. Segundo Arny e Rowe (1991), D. bryoniae precisa de apenas $1 \mathrm{~h}$ de molhamento foliar para infectar folhas de cucurbitáceas, e tempos maiores de molhamento favorecem a expansão da lesão. Neste estudo, o primeiro aumento da doença iniciou-se após os 57 DAP, quando o crescimento vegetativo do hospedeiro já era bastante significativo. Arny e Rowe (1991), Keinath (1995) e Van Steekelenburg (1985) também as- 
sociaram maior progresso da doença após os 50 DAP com o maior desenvolvimento vegetativo da cultura e à densa cobertura das folhas inferiores, retardando a evaporação da umidade e prolongando o período de molhamento foliar. Entretanto, neste experimento a taxa de progresso se tornou exponencial apenas quando ocorreram as injúrias normalmente associadas à primeira colheita (74 DAP). Isto indica que o processo de colheita também pode ter uma função importante na aceleração da epidemia do crestamento do caule.

Perdas de produtividade devidas ao crestamento gomoso do caule

Foram constatadas diferenças significativas entre os tratamentos quanto à percentagem de área foliar doente $(\mathrm{P}<$ $0,01)$ e produtividade $(\mathrm{P}<0,05)$. A relação entre a percentagem de área foliar doente e doses de fungicida foi negativa e exponencial $(Y=18,224$. exp $(-0,0087 \mathrm{x}))$ com um ótimo de controle com clorotalonil $125 \mathrm{~g}+$ tiofanato metílico $50 \mathrm{~g}$ (Figura 2A). A eficiência máxima de controle ocorreu a partir das doses comercias de 250 g/100 L, aproximando-se da recomendação comercial (ANDREI, 1999), que é de $200 \mathrm{~g}$ do p.c. (100ml i.a. clorotalonil +40 g i.a. de tiofanato metílico)/100 L de água. Desta forma, o uso acima dessa dose não resultou no maior controle da doença, além de tornar-se oneroso ao produtor. Neste estudo, a doença atingiu 26,5\% da área foliar no tratamento em que não foi aplicado o fungicida, valor considerado alto, levando-se em conta que manchas foliares raramente ultrapassam $37 \%$ de severidade, em média (KRANZ, 1977). Assim, é importante que o produtor faça o tratamento preventivo da doença.

À medida que se aumentou a dose do fungicida ocorreu aumento na produtividade da melancia, com uma diferença de 10,3 t entre as produtividades obtidas no tratamento testemunha e na dose máxima do p.c. de clorotalonil + tiofanato metílico $(500 \mathrm{~g}$ p.c./100 L, Figura 2B), em relação linear com equação $Y=0,0186 x+45,223,\left(r^{2}=0,85\right)$.

$\mathrm{O}$ aumento da doença nas folhas resultou em perda direta na produtividade (Figura 3). A correlação entre os valores médios da produtividade (Y) e de

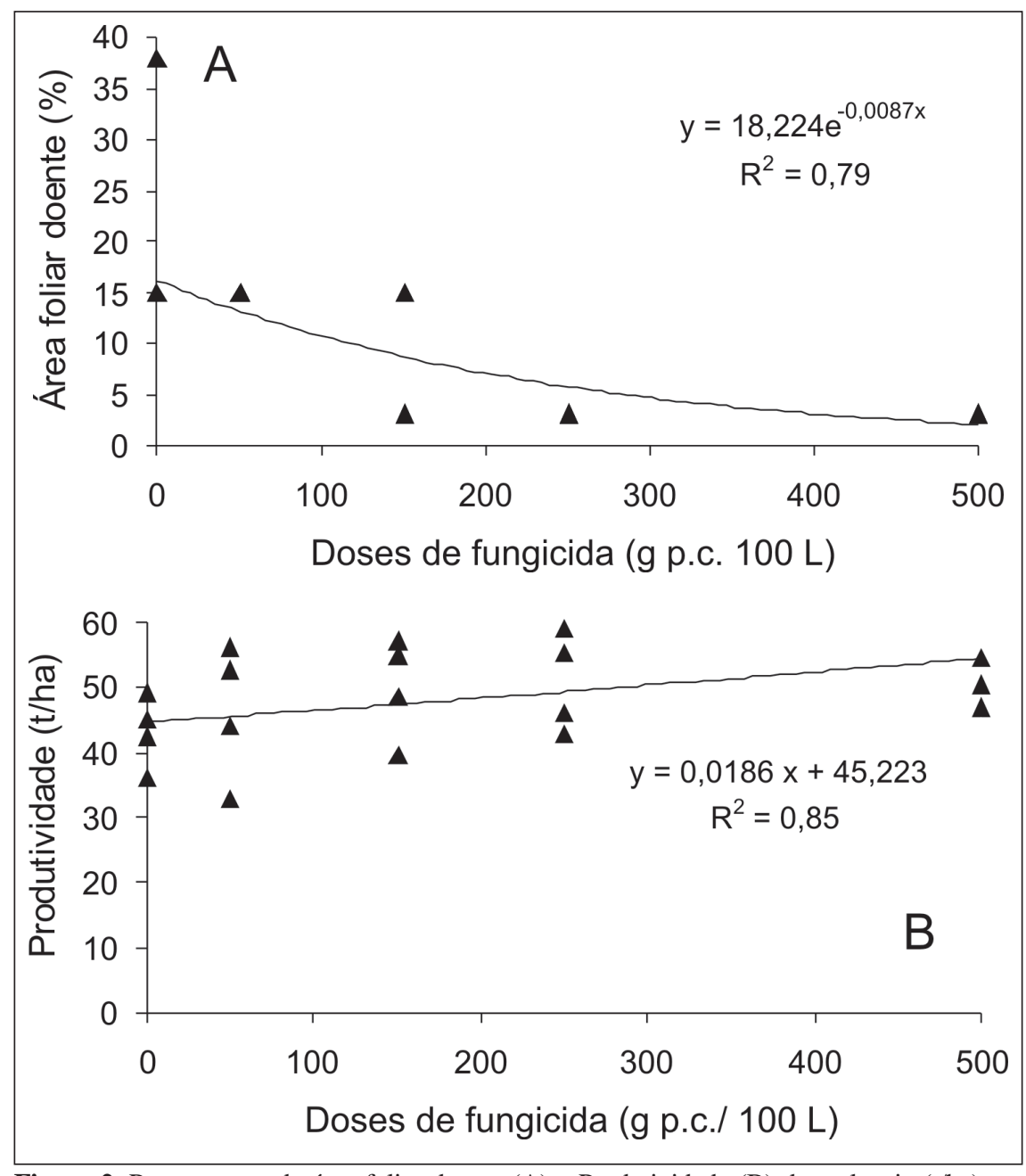

Figura 2. Percentagem de área foliar doente (A) e Produtividade (B) da melancia (t/ha) em função de diferentes doses do fungicida Clorotalonil + Tiofanato Metílico. Gurupi, UFT, 2003.

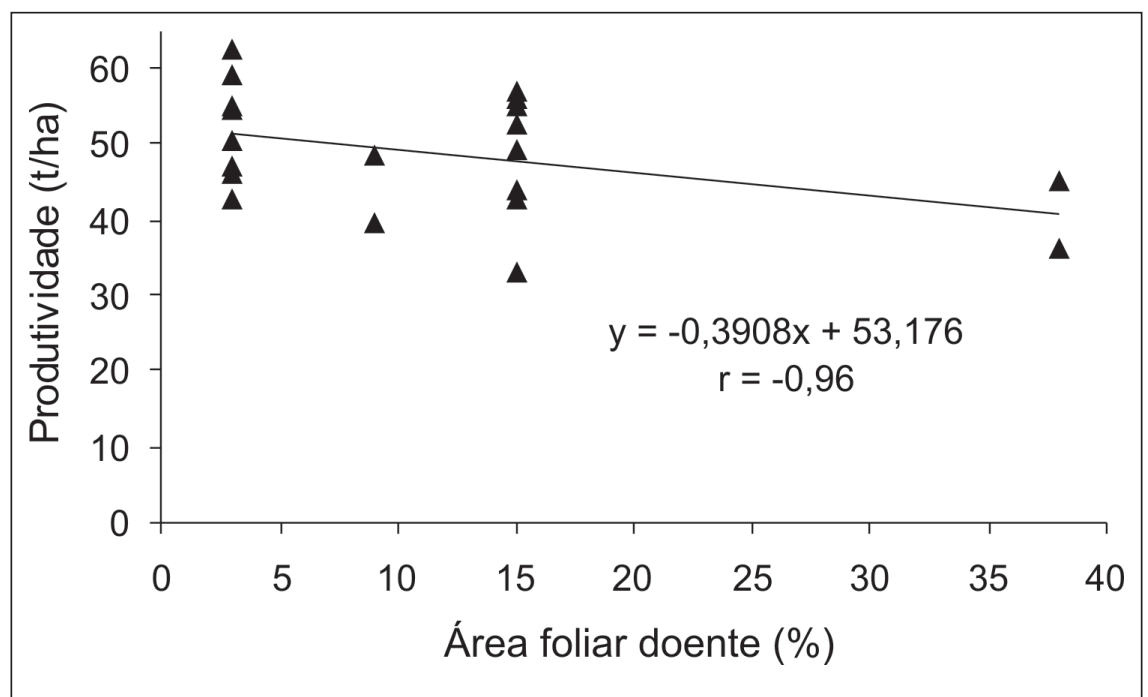

Figura 3. Correlação entre produtividade da melancia (cv. Crimson Sweet) e percentagem de área foliar doente. Gurupi, UFT, 2003.

área foliar doente $(\mathrm{x})$ foi linear, segun-

0,96). Quando se compararam os valodo a equação $Y=-0,3908 x+53,176(r=-\quad$ res de produtividade nas severidades de 
$3 \%$ de área foliar doente e de $26,5 \%$ (testemunha), houve decréscimo de 19,2\% na produtividade da melancia devido ao crestamento gomoso do caule, valor equivalente a 10,3 t/ha.

Outros estudos também enfatizaram que os fungicidas são uma importante ferramenta para prevenir a doença e reduzir as perdas na produção e na qualidade de frutos de melancia (KEINATH, 2001; LATIN, 1997). Keinath (2001) verificou que clorotalonil aplicado a intervalos regulares é bastante efetivo no controle do crestamento gomoso do caule, enquanto Keinath (1995), observou que a mistura de um protetor (clorotalonil) com um sistêmico (benomil) retardou a infecção e o desenvolvimento da doença. Resultado similar foi obtido neste estudo com a combinação de clorotalonil e tiofanato metílico.

Apesar de não se ter avaliado a qualidade dos frutos neste estudo, verificouse alto índice de frutos com escaldadura, principalmente nos tratamentos onde houve maior severidade da doença. Maynard e Hopkins (1990), também observaram que frutos queimados ocorreram em locais infestados e nos períodos de alta temperatura e intensa radiação solar que antecedeu a colheita.

Em conclusão, a redução de produtividade devida ao crestamento gomoso do caule da melancia pode chegar em 19,2\%, em condições de cultivo comercial no Tocantins. Os níveis de doença nas folhas têm alta correlação negativa com a produtividade de frutos. Para evitar perdas o produtor poderá utilizar o controle químico, que deverá ser preventivo ou nas fases iniciais de desenvolvimento da doença. Também ficou demonstrado que a doença progride de forma exponencial mesmo sob condições consideradas não muito favoráveis, sem chuvas e com baixo nível de inóculo inicial. A primeira colheita, que ocorreu por volta dos 70 DAP, contribuiu para o aumento da doença. Dessa forma, o produtor deverá evitar o pisoteio excessivo nos ramos.

\section{AGRADECIMENTOS}

Os autores agradeçem o apoio financeiro do CNPq, Processo n 474 194/ 2003-5. O segundo autor é bolsista de pesquisa do CNPq.

\section{LITERATURA CITADA}

ALENCAR, I. Melancia. Revista Safra, 2001. p43-45.

ANDREI, E. Compêndio de Defensivos Agrícolas. Guia Prático de Produtos Fitossanitários para Uso Agrícola, 6º ed. SP. 1999, pg.138.

ARNY, C.J.; ROWE, R.C. Effects of temperature and duration of surface wetness on spore production and infection of cucumbers by Didymella bryoniae. Phytopathology. v.81, p.206209, 1991.

BALA, G.; HOSEIN, F. Studies on gummy stem blight disease of cucurbits in Trinidad. Tropical Agriculture (Trinidad) v.63, p.195-197, 1986

CARDOSO, R.M.G.; FIGUEIREDO, M.B.; PALAZZO, D.; MARTINEZ, J.A. Epidemiology of fruit rot (Mycosphaerella melonis, (Pass.) Chiu e J.C. Walker) on italian squash (Cucurbita pepo L.). Arquivos do Instituto Biológico, v.41, n.1, p.35-37, 1974.

CÉSAR, N.S.; SANTOS, G.R. Doenças da cultura da melancia no Projeto Formoso, Tocantins. Fitopatologia Brasileira, Brasília. v.26 (Suplemento), p.411, 2001. (Resumo)

CHIU, W.F.; WALKER, J.C. Physiology and pathogenicity of the cucurbit black-rot fungus. Journal of Agricultural Research, v.78, p.589-615, 1949.

DIAS, R.C.S.; QUEIROZ, M.A.; MENEZES, M. Identificação de fontes de resistência em melancia a Didymella bryoniae. Horticultura Brasileira, Brasília, v.14, p.15-17, 1996.

EVERTS, K.L. First report of benomyl resistance of Didymella bryoniae in Delaware and Maryland. Plant Disease, v.83, p.304, 1999.

FAO-FAOSTAT Situação da produção e área de hortaliças no Brasil, 2002. Database Results disponível em: <http://apps.fao.org>

FIGUEIREDO, M.B.; CARDOSO, R.M.G.; ABRAHÃO, J. Perdas causadas pelo fungo Mycosphaerella melonis (Pass.) Chiu e J.C. Walker em aboboreira de moita. O Biológico, São Paulo, v.32, p.203-205, 1966.

KEINATH, A.P.; DUTHIE, I.A. Yield and quality reductions in watermelon due to anthracnose, gummy stem blight and black rot. p.77-90. in: Recent Research Developments in Plant Pathology, vol.2, Research Signpost, Trivandrum, India, 1998.

KEINATH, A.P. Effect of fungicide applications scheduled to control gummy stem blight on yield and quality of watermelon fruit. Plant Disease, v.85, n.1, p.53-58, 2001 .
KEINATH, A.P. Fungicide timing for optimum management of gummy stem blight epidemics on watermelon. Plant Disease, v.79, n.4, p.354-358, 1995.

KEINATH, A.P.; MAY, W.H.; DUBOSE, V.B. Comparison of eight fungicide intervals to control gummy stem blight on watermelon. Fungicides and Nematicides Tests, v.52, p.195, 1997.

KRANZ, J. A study on the maximum severity in plant diseases. Travaux dedies a G. ViennatBourgen, p.169-173.

LATIN, R. Evaluation of fungicides for control of gummy stem blight of watermelon. Fungicides and Nematicides Tests, v.52, p.196, 1997.

MALATHRAKIS, N.E.; VAKALOUNAKIS, D.J.

Resistance to benzimidazole fungicides in the gummy stem blight pathogen Didymella bryoniae on cucurbits. Plant Pathology, v.32, p.395-399, 1983.

MAYNARD, D.N.; HOPKINS, D.L. Watermelon fruit disorders. Horticulture Technology, v.9, p.155-161, 1999.

MCGRATH, D.J.; VAWDREY, L.; WALKER,

I.O. Resistance to gummy stem blight in muskmelon. HortScience. v.28, p.930-931, 1993. SANTOS, G.R.; CABRAL, M.M.; DIDONET, J. Podridão de frutos de melancia causado por Sclerotium rolfsii no Projeto Formoso, Tocantins. Fitopatologia Brasileira, Brasília. v.26 (Suplemento), p.412, 2001. (Resumo)

SANTOS, G.R.; CAFÉ-FILHO, A.C.; REIS, A.; LOPES, C.A. Progresso do crestamento gomoso do caule da melancia (Didymella bryoniae) em campo comercial. Fitopatologia Brasileira. Brasília. v.28 (Suplemento), p.226, 2003. (Resumo)

SCHENCK, N.C. Epidemiology of gummy stem blight (Mycosphaerella citrulina) on watermelon: ascospore incidence and disease development. Phytopathology, v.58, p.1420-1422, 1968.

SCHENCK, N.C. Watermelon disease incidence in central Florida. Plant Disease Reporter, v.44, p.556-568, 1960.

SITTERLY, W.R.; KEINATH, A.P. Gummy stem blight. p.27-28. in: Compendium of Cucurbit Diseases, T.A. Zitter, D.L. Hopkins \& C.E. Thomas, eds. APS Press, St Paul., 1996.

SUMNER, D.R.; HALL, M.R. Resistance of watermelon cultivars to Fusarium wilt and gummy stem blight. Biological Culture Tests. v.8, p.36, 1993.

SVEDELIUS, G.; UNESTAM, T. Experimental factors favouring infection of attached cucumber leaves by Didymella bryoniae. Transactions of British Mycological Society, v.71, p.89-97, 1978. VAN STEEKELENBURG, N.A.M. Influence of humidity on incidence of Didymella bryoniae on cucumber leaves and growing points under controlled environmental conditions. Netherlands Journal of Plant Pathology, v.91, p.253-264, 1985. WEHNER, T.C.; St. AMAND, P.C. Field tests for cucumber resistance to gummy stem blight in North Carolina. HortScience. v.28, p.327-329, 1993. 